\title{
AVALIAÇÃO DA CAPACIDADE DE JULGAMENTO \& TOMADA DE DECISÃO BASEADO NAS NORMAS INTERNACIONAIS DE CONTABILIDADE
}

\author{
JUDGEMENT CAPACITY EVALUATION \& DECISION MAKING BASED ON \\ INTERNATIONAL ACCOUNTING STANDARDS
}

\author{
IEDA MARGARETE ORO \\ Doutora em Ciências Contábeis e Administração- FURB. Professora \\ do Mestrado Profissional em Administração da UNOESC. Endereço: \\ Rua Nereu Ramos, 3777D / 89713-000 / Chapecó/SC / Brasil. \\ E-mail: ieda.oro@unoesc.edu.br
}

\section{ROBERTO CARLOS KLANN}

Doutor em Ciências Contábeis e Administração - FURB. Professor do Programa de Pós-Graduação em Ciências Contábeis da FURB. Endereço: Rua Antonio da Veiga, 140, Victor Konder / 89012-900 / Blumenau/SC / Brasil.

E-mail: rklann@furb.br

\section{RESUMO}

As normas internacionais vigentes evidenciam a necessidade do julgamento e tomada de decisão dos profissionais da contabilidade nas questões que envolvem o reconhecimento e a mensuração dos fatos contábeis. O objetivo deste estudo é avaliar a capacidade de julgamento e tomada de decisão de acadêmicos de ciências contábeis na resolução de questões que envolvem as normas internacionais. Em função das características do estudo, buscou-se, no desenvolvimento da análise, a associação com as heurísticas clássicas da tomada de decisão: representatividade, disponibilidade, ancoragem e ajuste. A pesquisa caracteriza-se como um estudo exploratório, survey com abordagem quantitativa. A amostra consistiu de 97 alunos do curso de graduação em Ciências Contábeis de uma universidade de Santa Catarina. O questionário selecionou 6 questões que envolvem julgamento e tomada de decisão e integram provas do Conselho Federal de Contabilidade. $\mathrm{Na}$ análise das heurísticas, que envolvem o julgamento e a tomada de decisão, constatou-se maior uso das heurísticas da disponibilidade e ancoragem e ajuste nas questões analisadas. A média percentual de acertos nas seis questões foi considerada baixa, contudo, não invalida os resultados, mas chama a atenção para o grau de racionalidade limitada nas decisões. É preciso ressaltar que os vieses cognitivos podem ser provocados pelo uso das heurísticas. Os achados da pesquisa revelam pontos significativos e que reforçam a importância do julgamento e tomada de decisão na formação acadêmica, como habilidade do Contador.

Palavras-chave: Julgamento. Tomada de Decisão. Heurísticas. Normas Internacionais de Contabilidade.

\section{ABSTRACT}

The current international standards emphasize the need for judgment and decision making of accounting professionals on issues involving the recognition and measurement of financial 
facts. The aim of this study is to evaluate the judgment and decision making of accountancy academic professionals in resolving issues involving international standards. Depending on the characteristics of the study we sought to develop the analysis, the association with the classic heuristic decision making, such as representativeness, availability, anchoring and adjustment. The research is characterized as an exploratory study, a Survey with a quantitative approach. The sample consisted of 97 graduating students in Accounting from a University of Santa Catarina. The questionnaire selected 6 issues involving judgment and decision-making and integrate evidence from the Federal Accounting Council. In the analysis of heuristics that involve judgment and decision-making, it was noticed an increasing use of heuristics of availability and anchoring and adjustment in the analyzed issues. The average percentage of correct answers in the six issues was considered low; however, it does not invalidate the results, but it draws attention to the degree of bounded rationality in decision making. Thus, it must be emphasized that the cognitive biases may be caused by the use of heuristics. The survey findings reveal important points that reinforce the importance of judgment and decision making in the academic training as an accountant skill.

Keywords: Judgment. Decision Making. Heuristics. International Accounting Standards.

\section{INTRODUÇÃO}

As normas internacionais vigentes aumentaram o grau de julgamento e tomada de decisão sobre os fatos contábeis que envolvem o processo de reconhecimento, mensuração e divulgação da informação contábil, e, nesse caso, ludícibus, Martins, Gelbcke e Santos (2010) adverte que exige do contador o exercício do julgamento. Para Dantas e Macedo (2013, p. 1), a "nova forma de se fazer contabilidade no Brasil traz à tona a preocupação sobre o preparo dos profissionais de contabilidade para lidarem com essa mudança e quais são os elementos cognitivos presentes no processo de tomada de decisão desses profissionais".

A contabilidade por meio da normatização contábil tem evoluído constantemente, e "tem se mostrado como influenciável, e deveras influenciada, pela cultura, pela economia, pelo pensamento jurídico, pelo poder, pelos interesses em jogo etc." (Martins et al., 2007, p.2). A mudança da contabilidade baseada em regras para uma contabilidade baseada em princípios aumentou o grau de julgamento exigido pelos responsáveis pela elaboração das demonstrações contábeis (Ernest Young \& Fipecafi, 2010).

Estudos sobre julgamento e tomada de decisão residem na prescrição de formas exitosas de tomar decisões seguras em situações de jogos (Hastie, 2001). Como muitas das funções cognitivas, a Tomada de Decisão traz uma dificuldade intrínseca para pesquisadores da área comportamental: é um fenômeno que só pode ser conhecido pelo comportamento em situações de decisão e pelas inferências que se faz a partir desses comportamentos (César, Akamine Jr. \& Perez, 2011).

Os dois motivos principais para a investigação nas ciências do comportamento são o desenvolvimento das teorias científicas e a resolução de problemas que ocorrem na vida cotidiana. Historicamente a pesquisa comportamental foi dividida em duas correntes distintas: julgamento e tomada de decisão (Hastie, 2001).

O ano de 2010 tem sido considerado um divisor da contabilidade no Brasil, em função da adoção plena das empresas ao padrão IFRS, considerada mais complexa que as antigas normas, exigindo mais julgamento e tomada de decisão do Contador. As Leis 11638/2007 e $11941 / 09$ e as normas internacionais de contabilidade emitidas pelo IASB e implementadas no Brasil pelo CPC e órgãos reguladores como a CVM e o CFC, entre outras, têm como premissa o uso de princípios do que de regras, facultando maior julgamento $e$ análise, consequentemente maior qualidade e utilidade das demonstrações contábeis (Lemes \& Carvalho, 2010; ludícibus et al., 2010 ).

Nesse sentido, o comportamento racional torna-se muito importante e faz com que os indivíduos tratem as informações de forma objetiva e não tenham tendências, propensões ou aversões. Nas decisões estão envolvidos os processos psicológicos que mostram constantemente que as pessoas as tomam de forma pouco racional (Pinto, 2012). 
Neste contexto, a questão que se apresenta nesta pesquisa é: Qual a capacidade de julgamento e tomada de decisão dos acadêmicos de ciências contábeis na resolução de questões que envolvem as normas internacionais? Os estudos sobre julgamento geralmente têm como foco verificar como as pessoas interpretam e decidem em situações de sugestões múltiplas e conflitantes sobre situações diversas. Em contraste, a tomada de decisão envolve escolher entre várias opções (Hastie, 2001; Eysenck \& Keane, 2007).

O objetivo desta pesquisa é avaliar a capacidade de julgamento e tomada de decisão de acadêmicos de ciências contábeis, na resolução de questões relacionadas às normas internacionais. Para atingir o objetivo geral, delinearam-se dois objetivos específicos: a) verificar se os alunos que cursaram a disciplina de noções de contabilidade internacional têm melhor desempenho na resolução das questões que envolvem capacidade de julgamento e tomada de decisão; b) investigar se os alunos que tem mais experiência na área contábil apresentam melhor desempenho na resolução das questões que envolvem julgamento e tomada de decisão. Em função das características do estudo, buscou-se no desenvolvimento da análise, a associação com as heurísticas clássicas da tomada de decisão: representatividade, disponibilidade, ancoragem e ajuste.

As normas internacionais de contabilidade estão presentes em muitos componentes curriculares do núcleo de formação profissional e teórico-prática do bacharel em ciências contábeis, pela necessidade da atualização dos conteúdos da formação do Contador. No entanto, a sugestão de inclusão de disciplina que abordasse as normas internacionais de contabilidade ocorreu pelas diretrizes curriculares nacionais no Parecer CNE/CES 10/2004, no Art. 5. Sugeriam a importância de incluir conteúdos que contemplassem "conhecimento do cenário econômico e financeiro, nacional e internacional, de forma a proporcionar a harmonização das normas e padrões internacionais de contabilidade".

Apesar de não ser obrigatório o oferecimento da disciplina de Contabilidade Internacional, a partir da Resolução emitida em 2004, vários cursos de Ciências Contábeis no Brasil a incluíram nas matrizes curriculares. Niyama, Botelho, Correa \& Santana $(2008$, p.114) ressaltam que das 888 instituições brasileiras observadas, "286 (32,20\%) encontram-se nas capitais dos estados brasileiros e, destas, $183(20,61 \%)$ publicaram suas grades curriculares na Internet. Porém, em apenas $44(24,04 \%)$ grades curriculares foi encontrada disciplina Contabilidade Internacional, ou similar". No entanto, constatou-se que existe uma simetria na quantidade de disciplinas de Contabilidade Internacional ou similares nas regiões do Brasil.

Este estudo traz como contribuição uma abordagem comportamental relacionada às normas internacionais de contabilidade e aspectos comportamentais que envolvem julgamento e processo decisório com acadêmicos de ciências contábeis. A aplicação empírica de pesquisas ligadas à avaliação da capacidade de tomada de decisão é útil no sentido de alinhar a teoria com a prática profissional.

\section{JULGAMENTO E TOMADA DE DECISÃO NA CONTABILIDADE}

O julgamento e a tomada de decisão estão presentes em muitas situações da área contábil. Envolvem a necessidade de estimar, mensurar, reconhecer e estabelecer critérios, como, por exemplo, a depreciação, a vida útil econômica, o valor recuperável, entre outros. O êxito do julgamento dos fatos contábeis pelos profissionais da contabilidade no que tange ao processo de mensuração e reconhecimento da informação depende do nível de conhecimento do assunto, ou de bases confiáveis para estimar ou definir critérios claros e objetivos.

A relação da contabilidade com as teorias comportamentais vem sendo discutida na literatura internacional há aproximadamente 50 anos (Birnberg, Luft \& Shield, 2007). A pesquisa em contabilidade com foco nas mudanças econômicas e mecanismos de mercado está entre os tipos mais pesquisados na área comportamental (Birnberg, 2011). Na década de 1970, iniciou-se a investigação na área contábil usando a teoria da psicologia cognitiva para estudar como os indivíduos utilizam subjetivamente informações da contabilidade para tomar decisões (Kahneman \& Tversky, 1979; Birnberg et al. 2007).

A base da literatura comportamental indica que há diferenças entre o julgamento e a tomada de decisão. A tomada de decisão, segundo Eysenck e Keane (2007, p. 460), "envolve 
resolução de problemas, pois os indivíduos tentam fazer a melhor escolha a partir de uma série de opções". Enquanto que o julgamento é avaliado pelo grau de precisão e pode ter consequência indireta por meio das decisões tomadas (Havey 2001 como citado em Eysenck \& Keane, 2007). Nesse sentido, a tomada de decisão refere-se a todo o processo de escolha de um curso de ação (Hastie, 2001).

No caso da pesquisa sobre julgamento e tomada de decisão, existem três quadros teóricos que fornecem a motivação para pesquisa atual e futura, conforme Hastie (2001): (a) teoria tradicional da utilidade esperada, mais proeminentemente representada por Von Neumann e Morgenstern (1947), e a teoria dos prospectos por Kahneman e Tversky (1972), que se concentra em escolha e comportamento do processo decisório; (b) teorias cognitivas algébricas que aborda o julgamento e a estimativa; e (c) teorias cognitivas computacionais que abordam a percepção da mente, funções inferencial e mnemônico.

As decisões em geral possuem um nível maior ou menor de complexidade. Segundo Kaufmann (1981, p. 14), "um dos fatores menos evidentes que torna difícil a decisão nas ações humanas é a complexidade do mundo moderno". Ou seja, "vivendo no meio desta complexidade estamos mais ou menos condicionados a ela, mas nossos embaraços começam quando as circunstâncias geram decisões cujas consequências consideramos importantes".

A decisão é o "processo que leva direta ou indiretamente a escolha de, ao menos, uma dentre diferentes alternativas, todas estas candidatas a resolver determinado problema" (Gomes, 2007, p.1). No processo de tomada de decisão, as pessoas buscam recursos simplificados que são mais conhecidos como heurísticas. As heurísticas mais frequentes são: da representatividade, disponibilidade e ancoragem e ajuste. Matlin (2003) menciona que as heurísticas são estratégias que geralmente produzem uma solução certa. Muitas vezes, o ser humano falha em discernir as limitações dessas heurísticas e nem sempre toma a decisão mais sensata. Utiliza-se de experiências anteriores ou até mesmo de crenças, para tomar decisões.

As pessoas também se utilizam das heurísticas para conviver com a racionalidade limitada, simplificando o processo de tomada de decisão (Dorow, Macedo Júnior, Nunes, Reina \& Maximiniano, 2010). A heurística de representatividade, segundo Kahneman e Tversky (1979) é usada frequentemente quando se julga uma amostra como representativa se ela for semelhante à população para a qual foi selecionada. Marin (2009) lembra que a heurística da representatividade ocorre quando ao realizar um julgamento de indivíduo ou de um evento tende-se a procurar características que correspondam a representações vividas anteriormente.

Com relação à heurística da disponibilidade, Sternberg (2010) ressalta que a maioria de nós emprega, pelo menos eventualmente, por meio de julgamentos feitos com base no grau de facilidade com que se pode trazer à lembrança aquilo que se percebe como situações relevantes de um fenômeno. Para Marin (2009), esse tipo de heurística pode ter uma estratégia gerencial de tomada de decisão muito útil, uma vez que eventos de maior frequência geralmente também são mais lembrados.

A "heurística de ancoragem e ajuste está relacionada à disponibilidade pela qual as pessoas ajustam suas avaliações por meio de certos pontos de referência denominados de âncoras de finalidades" (Sternberg, 2010, p. 440). Matlin (2003) ressalta que essa heurística costuma conduzir a uma resposta razoável, no entanto, muitas vezes, depende da heurística da disponibilidade, porque as informações disponíveis servem como âncora. De acordo com essa teoria os tomadores de decisão partem de um ponto até os ajustes na decisão final. Os valores servem como âncoras e podem ser dados históricos, da maneira como o problema é exposto ou de informações aleatórias, gerando maior dificuldade de sucesso na tomada de decisão (Bazerman, 2004).

Para Robbins (2004, p.128) o "indivíduo toma decisões para obter os melhores resultados, realiza este processo de forma racional, pois seus objetivos são a maximização de valores". Enquanto que Bazerman (2004, pp. 3-5) destaca que o julgamento faz parte dos "aspectos cognitivos do processo de tomada de decisões". O autor sugere que para um modelo racional de tomada de decisão, deve-se: 1) delimitar claramente o problema; 2) ter critérios definidos; 3) ponderar acuradamente todos os critérios; 4) conhecer as alternativas relevantes; 5) avaliar acuradamente cada alternativa com base nos critérios definidos; 6) avaliar as alternativas e escolher as de maior valor percebido. 
A aderência às normas internacionais de contabilidade não consiste somente em um processo operacional, visto que alguns conceitos culturais deverão ser modificados. Sabe-se que no Brasil até a mudança aos padrões internacionais, as normas eram, na maioria, baseadas na doutrina do direito romano (code law), ou seja, em regras, ao contrário das IFRS, cuja principal característica é ser baseado em princípios. Considerando a natureza de um sistema contábil baseado em princípios, em que são estabelecidos preceitos gerais que servem de referência para o julgamento profissional, a melhor forma de evidenciar a essência econômica das operações, o modelo é mais apropriado onde há uma tradição jurídica consuetudinária (common law) (Dantas, Niyama, Rodrigues \& Mendes, 2010).

Quando a normatização é dominada por "regras detalhadas (rules oriented), existem regras para tudo: se acontecer isto, faça aquilo, se acontecer a alternativa a, faça a pergunta b, se esta for positiva, faça tal coisa etc." (Martins et al., 2007, p. 10). E é provável que as soluções são encontradas a partir da leitura minuciosa das regras. Não é preciso criar, o julgamento se reduz às classificações de onde o fato contábil se encaixa (Martins et al., 2007).

Nas normas vigentes, as informações sobre julgamento indicam que a entidade deve divulgar, no resumo das principais práticas contábeis ou em notas explicativas, os julgamentos que envolvem estimativas utilizadas no processo de aplicação das práticas contábeis e que possuem efeito mais significativo nos valores reconhecidos nas demonstrações contábeis. $O$ Pronunciamento Conceitual Básico do Comitê de Pronunciamentos Contábeis - CPC (CPC 00, item 86, p. 24) estabelece que, "em muitos casos, o custo ou o valor precisa ser estimado; o uso de estimativas razoáveis é uma parte essencial da preparação das demonstrações contábeis e não prejudica a sua confiabilidade".

Os estudos que envolvem a formação acadêmica de ciências contábeis e que tratam sobre capacidade de avaliação de julgamento e tomada de decisão são considerados raros na literatura científica (Maia, 2012). As provas do exame de suficiência e de qualificação técnica do Conselho Federal de Contabilidade são estruturadas em conhecimento e cálculo, julgamento e memorização. No entanto, no primeiro exame de suficiência de 2012 e no segundo de 2011, apenas 4 questões foram consideradas de julgamento e integravam o rol de perguntas da prova (Maia, 2012). Em função das normas contábeis vigentes, esse é um assunto que deverá fazer parte de novos estudos. $\mathrm{Na}$ sequência, alguns estudos comportamentais realizados no Brasil com foco em processos decisórios em contabilidade.

\subsection{Estudos comportamentais de processos decisórios em contabilidade}

Os seres humanos são dotados de habilidades e de inteligência que lhes permitem decidir entre diversas opções. Algumas decisões não possuem regras estabelecidas, outras exigem a necessidade de julgamento sobre os fatos. Pesquisas comportamentais envolvendo processo decisório são alvo de diversos estudos no Brasil.

Lima (2007) observou o comportamento de usuários da informação contábil na forma de apresentação e evidenciação dos relatórios contábeis e sua influência nas decisões dos usuários. O estudo foi realizado por meio de experimentos com alunos de instituições públicas e privadas. Os resultados comprovaram o efeito formulação em cinco das seis situações apresentadas.

Cardoso e Oyadomari (2010) pesquisaram a existência da fixação funcional no ambiente de informação contábil. No ambiente contábil brasileiro, com a mudança na regulação Contábil, avalia-se que os usuários da informação podem sofrer com esse tipo de efeito uma vez que a experiência passada pode pesar em sua decisão. A pesquisa utilizou-se de dois experimentos baseados em situações contábeis, alteradas a partir da Lei 11.638/07. Foi utilizada uma amostra de 120 questionários aplicados entre profissionais de mercado e estudantes com e sem experiência. Os resultados da pesquisa confirmaram a existência da fixação funcional, bem como a não influência da experiência profissional no processo de decisão quando comparados os profissionais que atuam no mercado e os estudantes.

Macedo e Fontes (2009) analisaram o impacto da racionalidade limitada no processo decisório, num ambiente de análise contábil-financeira. Para tanto, foi aplicado um questionário a 91 analistas, convidados a tomar uma decisão ou emitir uma opinião acerca dos aspectos abordados em cada uma das questões. Os resultados mostram que, de maneira geral, os usos 
das heurísticas de julgamento, bem como da teoria dos prospectos, levam a vieses, que desviam a escolha de uma alternativa meramente racional.

Silva e Gonçalves (2011) verificaram se a demonstração proforma influencia o usuário da informação contábil no processo decisório. Os dados foram coletados por meio de dois tipos de questionários aplicados a um total de 355 estudantes de Ciências Contábeis. Num primeiro tipo, somente as demonstrações contábeis baseadas nos Princípios Fundamentais foram informadas; num segundo tipo, além disso, foi informada também a Demonstração proforma. Os resultados mostraram que a imobilização do patrimônio líquido exerce uma influência sobre os resultados. Mas que em geral a demonstração proforma não altera de maneira significativa o usuário da informação contábil no processo decisório.

O processo de decisão em ambiente contábil, sob a ótica da Teoria dos Prospectos, demostra que as decisões são baseadas principalmente em julgamento, contribuindo para consciência das imperfeições dos julgamentos e decisões (Pinto, 2012). A pesquisa foi aplicada aos profissionais da contabilidade. Nos resultados, constatou-se que as questões que envolvem certeza no campo dos ganhos são as mais procuradas entre os respondentes. É possível identificar a presença do Efeito Framing. Em relação ao gênero, é possível identificar maior impacto do Efeito Framing nos homens do que nas mulheres.

A capacidade de Julgamento e Tomada de Decisão (J\&TD) também tem sido tema de estudos na área do ensino. Maia (2012) estudou como J\&TD vem sendo ensinado nos cursos de Graduação em Ciências Contábeis, quando é iniciada a formação de competências e habilidades do profissional. Apesar da abordagem do assunto por algumas IESs, o ensino do J\&TD, diante da sua importância na aplicação das normas internacionais de contabilidade, ainda não é realizado de forma satisfatória. Xavier Filho, Dias, França, Silva e Vasconcelos (2015) analisaram a importância conferida à área de contabilidade por discentes do curso de Administração. A pesquisa abordou a análise de importância atribuída por meio de Influentes de Julgamento (IJ). Representam características sócioeconômicas que podem interferir no julgamento. Entretanto, mesmo considerando esses influentes, não se observou diferença estatística após os discentes terem cursado a disciplina. Outro estudo, realizado por Moreira, Firmino, Santos, Silva e Silva (2015), investigou a uniformidade da qualidade dos serviços realizados pelas firmas de auditoria no Brasil sobre as companhias abertas brasileiras, fundamentando-se na adoção da Deliberação CVM n 564/08. Os resultados revelaram ausência de qualidade uniforme no relatório dos auditores independentes com base na adoção ao ajuste a valor presente.

\section{MÉTODO DE PESQUISA}

Esta seção apresenta o delineamento e a amostra da pesquisa, bem como os conteúdos do questionário aplicado aos alunos pesquisados, além de uma breve contextualização da disciplina de Contabilidade Internacional no Brasil.

\subsection{Delineamento e amostra da pesquisa}

Esta pesquisa caracteriza-se como exploratória e survey com abordagem quantitativa. Creswell (2007, p. 161) define pesquisa survey como sendo "uma descrição quantitativa ou numérica de tendências, atitudes ou opiniões de uma população ao estudar uma amostra dela". A abordagem quantitativa foi utilizada para identificar os percentuais de respostas certas e erradas dos dois grupos de alunos definidos para o estudo. A relação das respostas com as heurísticas representam estratégias gerais que normalmente produzem uma solução correta.

A população da pesquisa consistiu-se de 170 alunos de graduação de Ciências Contábeis que correspondem a 4 turmas diferentes, uma em cada campus da Universidade. A amostra caracteriza-se como não probabilística e intencional, pois parte de um universo restrito, visto que os participantes foram selecionados a partir da conveniência dos pesquisadores, e resultou em 102 acadêmicos. Desses, 5 foram excluídos, pois os questionários apresentaram inconsistências (não responderam alguma das questões, ou deram mais de uma resposta na mesma questão). Os participantes foram divididos em dois grupos. $\mathrm{O}$ primeiro corresponde a 50 alunos que cursaram a disciplina de noções de contabilidade 
internacional nos meses de agosto e setembro de 2012 e o questionário foi aplicado nos dias 27 e 28 de setembro de 2012. O segundo grupo, de 47 alunos, cursou a disciplina em outubro e novembro de 2012 e o questionário foi aplicado nos dias 01 e 02 de outubro de 2012 . O instrumento de coleta dos dados foi aplicado pelos coordenadores de curso nas datas mencionadas.

Os alunos participantes estão no quarto ano e já tiveram no decorrer do curso, em outras disciplinas de contabilidade, conteúdos que envolvem as normas internacionais. No momento de realização da pesquisa, $85 \%$ dos conteúdos do núcleo específico de contabilidade já foram cursados. A escolha da disciplina se justifica em função do propósito desta pesquisa.

\subsection{Conteúdos do questionário da pesquisa}

O instrumento de pesquisa inicialmente solicitou respostas a 3 perguntas fechadas para o perfil (gênero, faixa etária e experiência na área contábil). Posteriormente, para atingir o objetivo, solicitou resolução e resposta de 6 questões identificadas como julgamento no estudo de Maia (2012) e consequentemente exige a tomada de decisão. Todas as questões constam das provas de Qualificação Técnica e Exame de Suficiência do Conselho Federal de Contabilidade. Na Tabela 1, o conteúdo, fundamentação, regulamentação e origem das questões (Exame de Qualificação Técnica EQT e Exame de Suficiência ES).

Tabela 1

Questões que envolvem julgamento

\begin{tabular}{|c|c|c|c|c|}
\hline $\begin{array}{l}\text { N.ques } \\
\text { tão }\end{array}$ & Conteúdo & $\begin{array}{l}\text { Fundamentos } \\
\text { (IAS e CPC) }\end{array}$ & Regulamentação (CFC) & $\begin{array}{ll}\text { Origem } \\
\text { questão }\end{array}$ \\
\hline 01 & $\begin{array}{lcl}\text { Demonstrações consolidadas } & - \\
\text { determinação de quando consolidar } & \end{array}$ & $\begin{array}{l}\text { IAS 27; CPC } 36 \\
\text { (R1) (2009) }\end{array}$ & $\begin{array}{l}\text { 1.240/09 alt.; } .273 / 10 \mathrm{e} \\
1.351 / 11-\mathrm{NBC} \text { TG } 36\end{array}$ & EQT, 2010 \\
\hline 02 & Receitas reconhecimento & $\begin{array}{l}\text { IAS } 18 \\
\text { CPC30 (2009) }\end{array}$ & 1.187/09; NBC TG 30 & EQT, 2010 \\
\hline 03 & $\begin{array}{l}\text { Ativo não circulante mantido para venda } \\
\text { e operação descontinuada }\end{array}$ & $\begin{array}{l}\text { IFRS } 5 \text { CPC } 31 \\
(2009)\end{array}$ & 1.188/09; NBC TG 31 & EQT, 2010 \\
\hline 04 & Contratos de construção - mensuração & $\begin{array}{l}\text { IAS } 11 \\
\text { CPC } 17 \text { (2009) }\end{array}$ & 1.171/09; NBC TG 17 & EQT, 2010 \\
\hline 05 & $\begin{array}{l}\text { IFRS para PMEs combinação de } \\
\text { negócios - identificação do adquirente }\end{array}$ & $\begin{array}{l}\text { IFRS for SMES } \\
\text { CPC PME (R1) }\end{array}$ & $\begin{array}{l}1.255 / 09 ; 1.285 / 10 \\
1.319 / 10 ; 1329 / 11 \text { NBC } \\
\text { TG } 1000\end{array}$ & EQT, 2011 \\
\hline 06 & $\begin{array}{l}\text { Subvenção } \\
\text { reconhecimento }\end{array}$ & $\begin{array}{l}\text { IAS } 20 \text { CPC } 07 \\
\text { (R1) (2010) }\end{array}$ & $\begin{array}{l}1.305 / 10 \\
\text { NBC TG } 07\end{array}$ & ES, 2012 \\
\hline
\end{tabular}

Nota. Fonte: elaboração própria com base em Maia, K. I. C. (2012). O ensino de julgamento e tomada de decisão nos cursos de graduação em ciências contábeis no Brasil. Dissertação de mestrado. Escola Brasileira de Administração Pública e Empresas- EBAPE - FGV. São Paulo, Brasil. Recuperado em 29 julho, 2012, de http://bibliotecadigital.fgv.br/dspace/handle/10438/9909 e Conselho Federal de Contabilidade (2012). Exame de Qualificação Técnica e Exame de Suficiência. Recuperado em 10 agosto, 2012, de http://www.portalcfc.org.br/coordenadorias/desenvolvimento_profissional/ exames/exame_de_qualificacao_tecnica/

\subsection{Disciplina de Contabilidade Internacional}

A disciplina de Contabilidade Internacional foi inserida na matriz curricular a partir da sugestão do Parecer CNE/CES 10 de 2004 e integrada na matriz curricular do curso de ciências contábeis da IES que realizou este estudo em 2009, a partir da necessidade de oferecer conteúdos relacionados à harmonização das normas e padrões internacionais de contabilidade. A disciplina é oferecida com 30 horas aula no oitavo período do curso.

A ementa da disciplina no projeto pedagógico prevê o oferecimento de conteúdos relacionados à forma de reconhecimento e mensuração que envolve as normas internacionais de contabilidade. No entanto, destaca-se que nesta pesquisa não foi observado se os conteúdos programáticos indicados nos planos de ensino dos professores que ministram as referidas disciplinas estavam relacionados aos itens específicos da Tabela 1. 


\section{DESCRIÇÃO E ANÁLISE DOS RESULTADOS}

Com a finalidade de responder ao problema de pesquisa foi aplicado um questionário com dois grupos de alunos. Na sequência os resultados do estudo. Primeiramente o perfil dos respondentes.

\subsection{Perfil dos alunos respondentes} resultados.

Quanto ao gênero e faixa etária dos alunos pesquisados, a Tabela 2 apresenta os

Tabela 2

Gênero e tempo de experiência na área contábil

\begin{tabular}{c|c|c|c|c|c|c|c|c}
\hline Gênero & $\begin{array}{c}\text { Experiência } \\
\text { até 1 ano }\end{array}$ & $\%$ & $\begin{array}{c}\text { Experiência } \\
+ \text { de 1 ano }\end{array}$ & $\%$ & $\begin{array}{c}\text { Sem } \\
\text { experiência }\end{array}$ & $\%$ & Total & $\%$ \\
\hline Feminino & 13 & 68 & 35 & 76 & 25 & 78 & 73 & 75 \\
Masculino & 6 & 32 & 11 & 24 & 7 & 22 & 24 & 25 \\
\hline Total & 19 & 100 & 46 & 100 & 32 & 100 & 97 & 100 \\
\hline
\end{tabular}

Nota. Fonte: dados da pesquisa.

Constatou-se que a amostra da pesquisa é representada por $75 \%$ dos respondentes do sexo feminino e $25 \%$ do sexo masculino. Com relação ao tempo de experiência na área contábil, com (-) de um ano, 19 responderam que a possuíam. Dessas, a maioria é do sexo feminino. No tempo de experiência, (+) de um ano, $76 \%$ também são do sexo feminino. Percebe-se igualmente um percentual significativo de acadêmicos sem experiência, 32 alunos não trabalham na área contábil, e cursam o último ano. A Tabela 3 apresenta a relação entre a faixa etária e o tempo de experiência dos alunos participantes.

Tabela 3

Relação entre o faixa etária e o tempo de experiência dos alunos

\begin{tabular}{c|c|c|c|c|c|c|c|c}
\hline Faixa Etária & $\begin{array}{c}\text { Experiência } \\
\text { até 1 ano }\end{array}$ & $\%$ & $\begin{array}{c}\text { Experiência } \\
\text { + de 1 ano }\end{array}$ & $\%$ & $\begin{array}{c}\text { Sem } \\
\text { experiência }\end{array}$ & $\%$ & Total & $\%$ \\
\hline Até 20 anos & 3 & 16 & 2 & 4 & 4 & 13 & 9 & 9 \\
De 21 a 25 anos & 15 & 79 & 31 & 67 & 21 & 66 & 67 & 69 \\
$\begin{array}{c}\text { De 26 a 30 anos } \\
\text { Acima de 31 }\end{array}$ & 0 & 0 & 9 & 20 & 5 & 16 & 14 & 14 \\
anos & 1 & 5 & 4 & 9 & 2 & 6 & 7 & 7 \\
\hline Total & 19 & 100 & 46 & 100 & 32 & 100 & 97 & 100 \\
\hline
\end{tabular}

Nota. Fonte: dados da pesquisa.

A maioria dos alunos que participaram da pesquisa possui de 21 a 25 anos, correspondendo a $69 \%$ da amostra. $E$, desses, $67 \%$ indicaram ter mais de um ano de experiência na área contábil. As faixas etárias que menos apresentaram observações na amostra foram até 20 anos e acima de 31 anos.

\subsection{Análise dos resultados da pesquisa}

Esta seção apresenta os resultados da pesquisa, comparando os índices de acerto das questões entre os dois grupos. Um grupo que já havia cursado (50 alunos) e outro que não havia cursado (47 alunos) a disciplina de noções de contabilidade internacional. Matlin (2003, p. 261) ressalta que "na tomada de decisão, estão em jogo o julgamento e a escolha entre diversas alternativas". Ou seja, quando se depara em situações de incerteza, utiliza-se o raciocínio dedutivo para buscar a solução.

a) Demonstrações consolidadas

A Tabela 4 apresenta a primeira questão com as alternativas de respostas e a Tabela 5 os percentuais de acertos e erros. O enunciado da questão está estruturado com base no CPC 36 (R1) (2009), que trata das demonstrações consolidadas. A resposta é a letra D. 
Tabela 4

\section{Primeira questão}

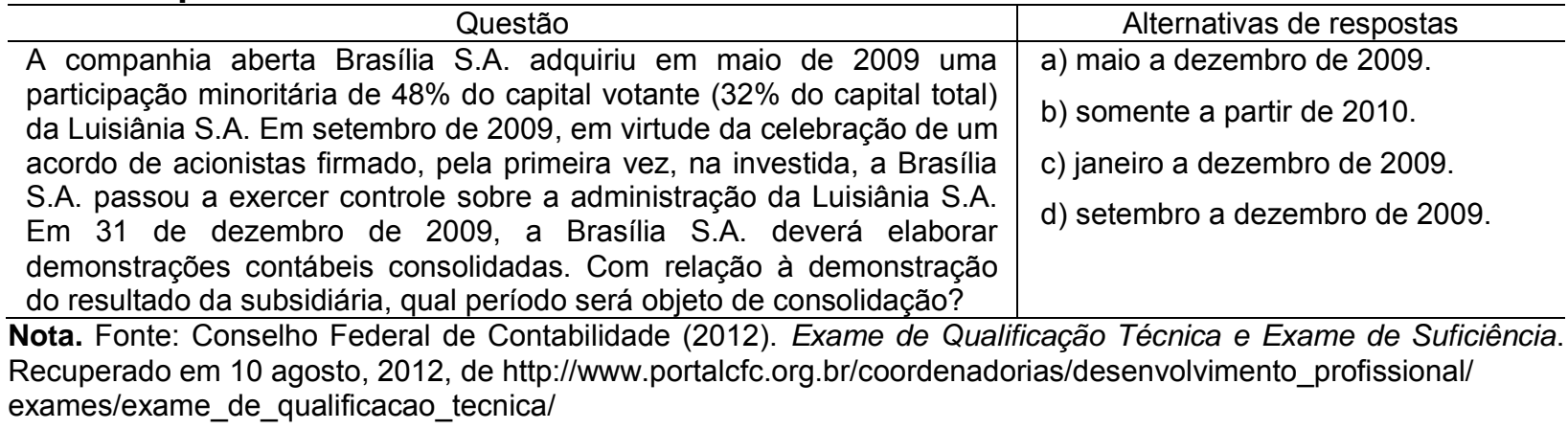

Percebe-se que o maior percentual de respostas recaiu sobre as alternativas erradas, $70 \%$ no Grupo 1 e $51 \%$ no Grupo 2, conforme Tabela 5.

\section{Tabela 5}

Quantidade de respostas certas e erradas da primeira questão

\begin{tabular}{l|c|c|c|c|c|c|c}
\hline Grupos & Certas & $\%$ & Erradas & $\%$ & Total & $\%$ \\
\hline Grupo 1 & 15 & 30 & 35 & 70 & 50 & 100 \\
Grupo 2 & 23 & 49 & 24 & 51 & 47 & 100 \\
\hline
\end{tabular}

Nota. Fonte: dados da pesquisa.

Nesta questão, constatou-se que o grupo 2, que não cursou a disciplina de contabilidade internacional, obteve a maior quantidade de acertos com êxito de $49 \%$ e consequentemente a menor quantidade de escolha de alternativas erradas. O julgamento incidiu sobre o período de objeto da consolidação da demonstração do resultado da subsidiária. $\mathrm{Na}$ análise dos dados, constatou-se que a maioria dos respondentes ficou indecisa entre a letra A (maio a dezembro de 2009) e a resposta da letra D (setembro a dezembro de 2009). Nesse caso, percebe-se uma questão de julgamento em que os alunos interpretaram e decidiram em situações de sugestões múltiplas com um nível de complexidade que estava relacionado ao período de tempo do objeto de consolidação. A heurística de ancoragem e ajuste explica os erros quando se faz estimativas sobre intervalos de tempo, dado o grau de incerteza da questão.

b) Reconhecimento de receitas

A segunda questão abordou o CPC 30 (2009), que trata do Reconhecimento das Receitas. A receita proveniente da venda de bens deve ser reconhecida quando forem satisfeitas as seguintes condições: a) a entidade tenha transferido para o comprador os riscos e benefícios mais significativos inerentes à propriedade dos bens; b) a entidade não mantenha envolvimento continuado na gestão dos bens vendidos em grau normalmente associado à propriedade nem efetivo controle de tais bens; c) o valor da receita possa ser confiavelmente mensurado; d) for provável que os benefícios econômicos associados à transação fluirão para a entidade; e) as despesas incorridas ou a serem incorridas, referentes à transação, possam ser confiavelmente mensuradas (RES CFC 1187/09). A Tabela 6 apresenta a questão 2 e a Tabela 7 apresenta as respostas dos alunos. A resposta é a letra D. 
Tabela 6

\section{Segunda questão}

\begin{tabular}{l} 
Questão \\
\hline 2. A empresa Joinville S.A., sediada em São Paulo, \\
vendeu uma máquina de laminar madeira no valor de \\
$\mathrm{R} \$ 50.000,00$ para a empresa Blumenau Ltda., \\
sediada em Mato Grosso do Sul. O faturamento \\
ocorreu no dia 5/2/2009; a saída da mercadoria \\
ocorreu no dia $6 / 2 / 2009$; e a entrega da máquina \\
ocorreu no dia $10 / 2 / 2009$. O contrato de venda prevê \\
que a empresa Joinville S.A. tem a obrigação de \\
instalar a máquina na empresa Blumenau Ltda., o que \\
demandará dois dias de trabalho. Finalmente, após um \\
período de inspeção e testes de 30 dias, se tudo \\
ocorrer conforme o que foi contratado, a compradora \\
emitirá um termo de aceite da máquina, liberando, \\
concomitantemente, o pagamento da obrigação \\
resultante da compra. De acordo com a NBC T 19.30- \\
Receitas, aprovada pela Resolução CFC n. ${ }^{\circ} 1.187 / 09$, \\
a ocasião CORRETA para o reconhecimento da \\
receita.
\end{tabular}

Alternativa de respostas instante se reconhecem na escrituração o direito a receber do cliente e a respectiva baixa dos estoques.

b) no momento da saída das mercadorias, pois nesse instante ocorre o fato gerador do Imposto sobre a Circulação de Mercadorias e Serviços (ICMS).

c) no momento da entrega das mercadorias ao cliente, pois neste instante o cliente declara que recebeu as mercadorias mediante assinatura no canhoto da Nota Fiscal.

d) quando o comprador aceitar a entrega e a instalação e a inspeção forem concluídos.

Nota. Fonte: Conselho Federal de Contabilidade (2012). Exame de Qualificação Técnica e Exame de Suficiência. Recuperado em 10 agosto, 2012, de http://www.portalcfc.org.br/coordenadorias/desenvolvimento_profissional/ exames/exame_de_qualificacao_tecnica/

O percentual de questões erradas nos dois grupos foi elevado, superando $70 \%$. $\mathrm{O}$ grupo 1 apresentou maior índice de acerto, de 24\%, enquanto que o grupo 2 teve $19 \%$, conforme Tabela 7.

Tabela 7

Quantidade de respostas certas e erradas da segunda questão

\begin{tabular}{l|c|c|c|c|c|c}
\hline Grupos & Certas & $\%$ & Erradas & $\%$ & Total & $\%$ \\
\hline Grupo 1 & 12 & 24 & 38 & 76 & 50 & 100 \\
Grupo 2 & 9 & 19 & 37 & 79 & 47 & 100 \\
\hline
\end{tabular}

Nota. Fonte: dados da pesquisa.

$\mathrm{Na}$ análise dos dados, a maior quantidade de respostas nessa questão incidiu sobre a resposta da letra A (no momento da emissão da nota fiscal, pois nesse instante se reconhecem na escrituração o direito a receber do cliente e a respectiva baixa dos estoques), que indica a regra geral de reconhecimento das receitas. No entanto, a resposta correta era letra D (quando o comprador aceitar a entrega e a instalação e a inspeção forem concluídos). Percebe-se que, o julgamento associou a heurística da disponibilidade e da ancoragem e ajuste, ou seja, o grau de facilidade com que se traz à lembrança aquilo que se percebe como ocorrências relevantes de um fato. A alternativa da letra $A$ trata do procedimento normal da venda de estoques, que normalmente associa-se como uma âncora no raciocínio da questão.

c) Ativo não circulante mantido para venda e operação descontinuada

A próxima questão refere-se ao Ativo não circulante mantido para venda e operação descontinuada - descontinuidade CPC 31 (2009). Essa norma tem como objetivo estabelecer a contabilização de ativos não circulantes colocados à venda e a apresentação e divulgação de operações descontinuadas. Os critérios de classificação dos ativos mantidos para venda: a) mensurados pelo menor entre o valor contábil até então registrado e o valor justo menos as despesas de venda, e que a depreciação ou a amortização desses ativos cesse; b) apresentados separadamente no balanço patrimonial e que os resultados das operações descontinuadas sejam apresentados separadamente na demonstração do resultado. A Tabela 8 apresenta a questão 3 e as alternativas de respostas. A Tabela 9 apresenta as respostas dos alunos. A resposta é a letra $\mathrm{C}$. 
Tabela 8

\section{Terceira questão}

\begin{tabular}{l|l}
\hline \multicolumn{1}{|c}{ Questão } & \multicolumn{1}{c}{ Alternativa de respostas } \\
\hline Uma entidade está reorganizando suas atividades em & a) Somente a máquina da unidade "Z" será \\
3 unidades industriais devido a uma redução & considerada como operação descontinuada. \\
significativa na demanda dos produtos por elas & b) As unidades " $X "$ e "Y" e a máquina da unidade "Z" \\
produzidos. As unidades "X" e "Y" terão suas & serão consideradas como operações descontinuadas. \\
atividades encerradas até final do exercício corrente. & c) As unidades "X" e "Y" serão consideradas como \\
$\mathrm{Na} \mathrm{unidade} \mathrm{"Z",} \mathrm{apenas} \mathrm{uma} \mathrm{máquina,} \mathrm{que}$ & operações descontinuadas. \\
corresponde a uma linha de produção será desativada & d) As unidades "X" e "Y" não serão consideradas \\
temporariamente, sendo feita a sua devida & operações descontinuadas. Pois serão apenas \\
manutenção e conservação até que haja um aumento & encerradas; e a máquina da unidade "Z" não será \\
na demanda dos produtos para a sua reativação. De & considerada como descontinuada, pois pode vir a ser \\
acordo com a NBC T 19.28 - Ativo Não Circulante & reativada quando houver aumento da demanda.
\end{tabular}

Mantido para Venda e Operação Descontinuada, assinale a opção que apresenta o CORRETO tratamento do ponto de vista de operações descontinuadas, no encerramento do exercício.

Nota. Fonte: Conselho Federal de Contabilidade (2012). Exame de Qualificação Técnica e Exame de Suficiência. Recuperado em 10 agosto, 2012, de http://www.portalcfc.org.br/coordenadorias/desenvolvimento_profissional/ exames/exame_de_qualificacao_tecnica/

$\mathrm{Na}$ terceira questão, percebe-se diferença significativa entre os dois grupos. O grupo 1 apresentou baixo percentual de acertos, apenas $12 \%$, enquanto o grupo 2 teve $43 \%$, conforme Tabela 9.

Tabela 9

Quantidade de respostas certas e erradas da terceira questão

\begin{tabular}{l|c|c|c|c|c|c}
\hline Grupos & Certa & $\%$ & Erradas & $\%$ & Total & $\%$ \\
\hline Grupo 1 & 6 & 12 & 44 & 88 & 50 & 100 \\
Grupo 2 & 20 & 43 & 27 & 57 & 47 & 100 \\
\hline
\end{tabular}

Nota. Fonte: dados da pesquisa.

$\mathrm{Na}$ análise das respostas, nos dois grupos, o julgamento recaiu na resposta da letra $\mathrm{D}$ (As unidades " $X$ " e " $Y$ " não serão consideradas operações descontinuadas. Pois serão apenas encerradas; e a máquina da unidade "Z" não será considerada como descontinuada, pois pode vir a ser reativada quando houver aumento da demanda). A resposta correta corresponde à alternativa da letra C (As unidades " $X$ " $e$ " $Y$ " serão consideradas como operações descontinuadas).

O julgamento nessa questão consistiu se a unidade " $Z$ " deveria ser considerada descontinuada no encerramento do exercício. Ou seja, a maioria dos respondentes não teve dúvida de que as unidades $\mathrm{X}$ e $\mathrm{Y}$ eram consideradas em descontinuidade. Percebe-se a associação da heurística da ancoragem e ajuste que relaciona a disponibilidade pela qual as pessoas ajustam suas avaliações por meio de certos pontos de referência denominados âncoras de finalidades. Matlin (2003) ressalta que essa teoria pode servir de âncora, os tomadores de decisão partem de um ponto inicial até os ajustes na decisão final. No entanto, percebe-se um viés cognitivo principalmente no Grupo 1, que evidencia uma distorção perceptual culminando num julgamento pouco acurado na resolução da questão.

\section{d) Mensuração dos contratos de construção}

A questão 4 observou o CPC 17 (2009) que trata da mensuração dos Contratos de Construção que recomenda que a receita do contrato deve compreender: (a) a quantia inicial da receita no contrato e (b) as variações no trabalho contratado, reivindicações e pagamentos por incentivos. O julgamento envolve um ambiente de incerteza e dimensionamento da estimativa da receita no contrato. A Tabela 10 apresenta a questão e as alternativas de respostas. A Tabela 11 apresenta os resultados. A resposta é a letra A. 
Tabela 10

\section{Quarta questão}

\begin{tabular}{l|l}
\hline \multicolumn{1}{|c|}{ Questão } & \multicolumn{1}{c}{ Alternativa de respostas } \\
\hline NBCT 19.21 - Contratos de Construção & a) Contratante e contratado podem acordar variações ou \\
menciona que a receita do contrato é medida pelo & reivindicações que aumentem ou diminuam a receita do \\
valor justo da retribuição recebida ou a receber. A & contrato em período subsequente àquele em que o contrato \\
mensuração da receita do contrato pode ser & foi inicialmente acordado. \\
afetada por incertezas que dependem do & b) A quantia da despesa estimada em contrato de preço fixo \\
desfecho de acontecimentos futuros. As & pode aumentar em consequência de cláusulas de aumento \\
estimativas necessitam, muitas vezes, ser & de custos. \\
revistas à medida que os acontecimentos & c) A quantia da receita do contrato pode diminuir como \\
ocorrem e as incertezas se resolvem. Por isso, a & consequência de penalidades provenientes de atrasos \\
quantia da receita do contrato pode aumentar ou & imputáveis a terceiros. \\
diminuir de um período para o outro. Assinale a & d) Quando o contrato de preço fixo está relacionado à \\
opção que apresenta o exemplo CORRETO & $\begin{array}{l}\text { conclusão de cada unidade, a receita do contrato permanece } \\
\text { desse tipo de acontecimento. }\end{array}$
\end{tabular}

Nota. Fonte: Conselho Federal de Contabilidade (2012). Exame de Qualificação Técnica e Exame de Suficiência. Recuperado em 10 agosto, 2012, de http://www.portalcfc.org.br/coordenadorias/desenvolvimento profissional/ exames/exame_de_qualificacao_tecnica/

$\mathrm{Na}$ questão 4, percebe-se maior concordância nas respostas entre os dois grupos. A questão indica que a mensuração da receita do contrato pode ser afetada por incertezas que dependem do desfecho de acontecimentos futuros, conforme Tabela 11.

Tabela 11

Quantidade de respostas certas e erradas da quarta questão

\begin{tabular}{l|c|c|c|c|c|c}
\hline Grupos & Certas & $\%$ & Erradas & $\%$ & Total & $\%$ \\
\hline Grupo 1 & 19 & 38 & 31 & 62 & 50 & 100 \\
Grupo 2 & 18 & 38 & 29 & 62 & 47 & 100 \\
\hline
\end{tabular}

Nota. Fonte: dados da pesquisa.

O enunciado da questão indica o fator tempo como ponto de conflito e de avaliação. $\mathrm{Na}$ análise das respostas, constatou-se que a ambiguidade na concepção dos alunos ficava entre a alternativa A (Contratante e contratado podem acordar variações ou reivindicações que aumentem ou diminuam a receita do contrato em período subsequente àquele em que o contrato foi inicialmente acordado) e a letra D (Quando o contrato de preço fixo está relacionado à conclusão de cada unidade, a receita do contrato permanece fixa na proporção das unidades concluídas).

A associação com a alternativa da letra $D$ do reconhecimento proporcional da receita do contrato pode indicar relação com a familiaridade e disponibilidade de informações. Matlin (2003) destaca que se o problema exigir que se lembre de exemplos. Nesse caso, enquadrouse em situações que representam a heurística da disponibilidade.

e) Combinação de negócios - identificação do adquirente - IFRS para PMEs

Na questão 5, questionou-se sobre IFRS para PMEs - Combinação de negócios identificação do adquirente. De acordo com NBC TG 1000, um adquirente deve ser identificado para todas as combinações de negócios. A adquirente é a entidade combinada que obtém o controle das outras entidades. A Tabela 12 apresenta a questão e a Tabela 13 os resultados da pesquisa. A resposta é a letra $D$. 
Tabela 12

\section{Quinta questão}

\begin{tabular}{|c|c|}
\hline Questão & Alternativa de respostas \\
\hline $\begin{array}{l}\text { De acordo com a NBC TG } 1000 \\
\text { - Contabilidade para Pequenas e } \\
\text { Médias Empresas, um adquirente } \\
\text { deve ser identificado para todas } \\
\text { as combinações de negócios. } \\
\text { Embora algumas vezes a } \\
\text { identificação da adquirente possa } \\
\text { ser difícil, existem normalmente } \\
\text { indicações de sua existência. } \\
\text { Assinale a opção que NÃO } \\
\text { apresenta indicação da } \\
\text { existência de adquirente. }\end{array}$ & $\begin{array}{l}\text { a) Se o valor justo de uma das entidades combinadas é significativamente } \\
\text { maior do que o valor justo da outra entidade combinada, a entidade com o } \\
\text { maior valor justo é, provavelmente, a adquirente. } \\
\text { b) Se a combinação de negócios é efetivada por meio de uma troca de títulos } \\
\text { patrimoniais ordinários com direito a voto por caixa ou outros ativos, a } \\
\text { entidade que está entregando caixa ou outros ativos é, provavelmente, a } \\
\text { adquirente. } \\
\text { c) Se a combinação de negócios resulta na administração de uma das } \\
\text { entidades combinadas, sendo capaz de dominar a seleção da equipe de } \\
\text { administradores da entidade combinada resultante, a entidade cuja } \\
\text { administração é capaz de dominar é, provavelmente, a adquirente. } \\
\text { d) Se o valor patrimonial de uma das entidades combinadas é } \\
\text { significativamente maior do que o valor patrimonial da outra entidade } \\
\text { combinada, a entidade com o maior valor patrimonial é, provavelmente, a } \\
\text { adquirente. }\end{array}$ \\
\hline
\end{tabular}

Nota. Fonte: Conselho Federal de Contabilidade (2012). Exame de Qualificação Técnica e Exame de Suficiência. Recuperado em 10 agosto, 2012, de http://www.portalcfc.org.br/coordenadorias/desenvolvimento_profissional/ exames/exame_de_qualificacao_tecnical

$\mathrm{Na}$ quinta questão, o nível de discordância entre os grupos foi maior, assim como nas alternativas de respostas. O grupo 1 apresentou o menor percentual de acertos, com 18\%, enquanto o grupo 2 exibiu melhor índice, com 36\%. A maioria das respostas erradas situou-se nas alternativas das letras $\mathrm{B}$ e $\mathrm{C}$, enquanto que a resposta correta é a letra $\mathrm{D}$, conforme Tabela 13.

Tabela 13

Quantidade de respostas certas e erradas da quinta questão

\begin{tabular}{l|c|c|c|c|c|c}
\hline Grupos & Certas & $\%$ & Erradas & $\%$ & Total & $\%$ \\
\hline Grupo 1 & 9 & 18 & 41 & 82 & 50 & 100 \\
Grupo 2 & 17 & 36 & 30 & 64 & 47 & 100 \\
\hline
\end{tabular}

Nota. Fonte: dados da pesquisa.

A análise interposta no enunciado da questão ressalta a necessidade de julgamento nas alternativas propostas pela menção da não indicação da existência de adquirente. Destaca-se que as três alternativas de respostas das letras (A, B e C) fazem parte da NBC TG 1000 (item 19.10). Pressupõe-se que a maioria dos respondentes desconheciam as formas de identificação do adquirente com o que determina a norma específica. Quando a heurística da disponibilidade é contaminada por fatores como desconhecimento do conteúdo leva a decisões incorretas na resolução de um evento.

\section{f) Receita de subvenção governamental}

A última questão abordou o CPC 07 (2010) que trata do reconhecimento da receita tendo como origem a Subvenção Governamental. O item 12 trata da contabilização: "uma subvenção governamental deve ser reconhecida como receita ao longo do período confrontada com as despesas que pretende compensar, em base sistemática, desde que atendidas as condições do Pronunciamento. A subvenção governamental não pode ser creditada diretamente no patrimônio líquido". A Tabela 14 apresenta a questão e respostas. Na Tabela 15 os resultados da pesquisa. A resposta corresponde a letra $C$. 


\begin{tabular}{|c|c|}
\hline Questão & Alternativa de respostas \\
\hline $\begin{array}{l}\text { Uma sociedade empresária recebeu uma subvenção } \\
\text { governamental, destinada a compensar as despesas } \\
\text { com contratação, treinamento e manutenção de uma } \\
\text { quantidade mínima de empregados durante os três } \\
\text { primeiros anos de funcionamento. O recebimento da } \\
\text { subvenção se deu mediante depósito em conta } \\
\text { corrente de livre movimentação, no momento da } \\
\text { assinatura do protocolo com o governo do estado. De } \\
\text { acordo com a NBC TG } 07 \text { - Subvenção e Assistência } \\
\text { Governamentais, o valor recebido pela sociedade } \\
\text { empresária deverá ser: }\end{array}$ & $\begin{array}{l}\text { a) reconhecido imediatamente no Patrimônio Líquido, } \\
\text { na conta Reserva de Incentivos Fiscais. } \\
\text { b) reconhecido imediatamente no resultado do período } \\
\text { e, uma vez apurado o resultado, registrado na conta } \\
\text { Reserva de Incentivos Fiscais. } \\
\text { c) registrado no passivo e reconhecido como receita ao } \\
\text { longo do período e confrontada com as despesas que } \\
\text { pretende compensar, em base sistemática. } \\
\text { d) registrado no patrimônio líquido e reconhecido como } \\
\text { receita ao final do período em que deverão ocorrer as } \\
\text { despesas que pretende compensar, e em base } \\
\text { sistemática. }\end{array}$ \\
\hline
\end{tabular}

Nota. Fonte: Conselho Federal de Contabilidade (2012). Exame de Qualificação Técnica e Exame de Suficiência. Recuperado em 10 agosto, 2012, de http://www.portalcfc.org.br/coordenadorias/desenvolvimento_profissional/ exames/exame_de_qualificacao_tecnica/

$\mathrm{Na}$ análise das respostas da questão 6 não houve consenso entre os respondentes no grupo 1, ou seja, constatou-se que todas as alternativas foram apontadas de forma proporcional, enquanto que no grupo 2 a alternativa que recebeu maior nota foi a opção da letra A (reconhecido imediatamente no Patrimônio Líquido, na conta Reserva de Incentivos Fiscais), conforme Tabela 15.

\section{Tabela 15}

\section{Quantidade de respostas certas e erradas da sexta questão}

\begin{tabular}{l|c|c|c|c|c|c}
\hline Grupos & Certas & $\%$ & Erradas & $\%$ & Total & $\%$ \\
\hline Grupo 1 & 13 & 26 & 37 & 74 & 50 & 100 \\
Grupo 2 & 14 & 30 & 33 & 70 & 47 & 100 \\
\hline
\end{tabular}

Nota. Fonte: dados da pesquisa.

A resposta correta na questão 6 é a letra C (registrado no passivo e reconhecido como receita ao longo do período e confrontada com as despesas que pretende compensar, em base sistemática). A base da mensuração da subvenção ocorre pelo recebimento dos valores mediante depósito na conta corrente da sociedade. Nesse caso, o julgamento está na forma de reconhecimento das contas patrimoniais e de resultado da entidade. A forma de reconhecimento e registro da subvenção governamental foi o principal ponto de julgamento da questão.

$\mathrm{Na}$ sequência, o total de acertos das questões 1 a 6 relacionado com o tempo de experiência dos participantes. 
Tabela 16

Comparativo dos acadêmicos com e sem experiência na área contábil

\begin{tabular}{c|l|c|c|c|c|c|c|c|c}
\hline Questão & \multicolumn{1}{|c|}{ Assunto } & $\begin{array}{c}\text { Total de } \\
\text { acertos }\end{array}$ & $\%$ & $\begin{array}{c}\text { Experiência } \\
(-)\end{array}$ & 1 ano & $\begin{array}{c}\text { Experiência } \\
+ \text { de 1 ano }\end{array}$ & SEC & $\%$ \\
\hline 1 & $\begin{array}{l}\text { Consolidação - } \\
\text { demonstrações financeiras }\end{array}$ & 38 & 39 & 5 & 27 & 22 & 48 & 11 & 34 \\
\hline 2 & Reconhecimento receitas & 21 & 22 & 3 & 16 & 13 & 28 & 5 & 16 \\
\hline 3 & Operação descontinuidade & 26 & 27 & 5 & 26 & 14 & 30 & 7 & 22 \\
\hline 4 & $\begin{array}{l}\text { Mensuração de Contratos } \\
\text { construção }\end{array}$ & 37 & 38 & 7 & 37 & 17 & 37 & 13 & 41 \\
\hline 5 & $\begin{array}{l}\text { Identificação do adquirente } \\
\text { IFRS para PMEs }\end{array}$ & 28 & 29 & 6 & 32 & 15 & 33 & 7 & 22 \\
\hline 6 & $\begin{array}{l}\text { Reconhecimento de } \\
\text { Subvenção Governamental }\end{array}$ & 27 & 28 & 2 & 11 & 19 & 41 & 6 & 19 \\
\hline & média & 30 & 30 & 5 & 25 & 17 & 36 & 8 & 26 \\
\hline
\end{tabular}

Nota. SEC - Sem experiência de contabilidade.

Fonte: dados da pesquisa.

$\mathrm{Na}$ Tabela 9, a média de acertos das seis questões dos dois grupos resultou em $30 \%$. A questão que apresentou o maior percentual de acertos foi a questão 1, com $39 \%$, e a questão 4, com 38\%, que tratam da consolidação das demonstrações financeiras e da mensuração de contratos de construção, respectivamente. Na primeira questão, o objeto de julgamento consistia em relação ao período de reconhecimento e, na questão quatro, a mensuração da receita do contrato que ocorre num ambiente de incerteza. A segunda questão apresentou o menor percentual de acertos dos dois grupos, trata do período de reconhecimento de receitas correspondendo a 22\% (CPC 30, 2009).

Compararam-se os estudantes com e sem experiência na área contábil (SEC). Percebe-se que os estudantes com $(+)$ de 1 ano de experiência na área contábil tiveram percentual de acertos, em média, de $36 \%$, e os sem experiência de contabilidade (SEC) apresentaram, em média $26 \%$, representando diferença de $10 \%$. O comparativo entre os estudantes que possuem experiência (+) de 1 ano com os que possuem (-) de 1 ano é semelhante com o resultado anterior, ou seja, $11 \%$ a maior. Os resultados apresentam evidências que a experiência adquirida na área contábil é um fator relevante para tomada de decisão. Cardoso e Oyadomari $(2010$, p. 1) ressaltam que a intenção "não é comprovar que esse fato é decisivo para a experiência profissional afetar a decisão do indivíduo, e sim demonstrar que esse tipo de análise pode ser efetuado de forma mais aprofundada em futuros estudos na área de contabilidade comportamental".

\section{CONCLUSÃO}

O artigo objetivou avaliar a capacidade de julgamento e tomada de decisão de acadêmicos de Ciências Contábeis na resolução de questões relacionadas às normas internacionais de contabilidade. O estudo realizou uma pesquisa survey, classificando os alunos em dois grupos: grupo 1 que cursou a disciplina e grupo 2 que não havia cursado a disciplina de Noções de Contabilidade Internacional. Foram selecionadas 6 questões de provas do Conselho Federal de Contabilidade (2010, 2011 e 2012) que exigiam julgamento. Em função das características do estudo, buscou-se a associação com as heurísticas clássicas da tomada de decisão: representatividade, disponibilidade, ancoragem e ajuste.

$\mathrm{O}$ estudo delineou dois objetivos específicos. O primeiro consistia em verificar se os acadêmicos que cursaram a disciplina de contabilidade internacional têm melhor desempenho nas questões que envolvem julgamento e tomada de decisão nas normas internacionais. Constatou-se que o desempenho dos acadêmicos não foi melhor depois de cursar a referida disciplina. Das 6 questões, apenas em duas, o grupo 1, que havia cursado a disciplina obteve melhor desempenho que o grupo 2, que não havia cursado. A disciplina de Noções de Contabilidade Internacional possui carga horária de apenas $30 \mathrm{~h} / \mathrm{a}$, o que pode ser uma limitação para os resultados encontrados pela pesquisa. 
No segundo objetivo, investigar se os alunos que tem $(+)$ de um ano de experiência na área contábil apresentam melhor desempenho nas questões que envolvem julgamento e tomada de decisão, constatou-se que os estudantes que possuíam (+) de um ano de experiência obtiveram um percentual maior de acertos em relação àqueles que têm (-) de 1 ano ou sem experiência na área contábil (SEC) coadunando com os resultados de Cardoso e Oyadomari (2010).

Nas questões que envolvem julgamento e tomada de decisão é normal empregar o raciocínio dedutivo na resolução das questões que apresentam ambiguidade nas respostas ou em que faltam informações (Matlin, 2003). Pela análise das heurísticas que envolvem o julgamento e a tomada de decisão, constatou-se maior uso das heurísticas da disponibilidade e ancoragem e ajuste nas questões analisadas. Numa síntese geral, a média percentual de acertos nas seis questões foi considerada relativamente baixa e corresponde a $30 \%$. No entanto, não invalida os resultados, mas chama a atenção para o grau de racionalidade limitada nas decisões. Contudo, é preciso lembrar que os vieses cognitivos podem ser provocados pelo uso das heurísticas, também observado por Macedo e Fontes (2009).

Constatou-se no levantamento geral (somando os acertos dos dois grupos) que a questão 1 que trata da consolidação das demonstrações financeiras e a questão 4 que versa sobre a mensuração de contratos de construção apresentaram desempenho superior $(\geq 38 \%)$, enquanto que a questão 2 que aborda o reconhecimento de receitas apresentou o pior desempenho, de $22 \%$. As demais questões 3, 5 e 6, que tratam da operação descontinuada, identificação do adquirente IFRS para PME e reconhecimento da receita de subvenção governamental, apresentaram desempenho médio de $28 \%$.

Por se tratar de uma pesquisa predominantemente quantitativa e aplicada em apenas uma IES, não se tem como generalizar as informações, mas como outras pesquisas dessa natureza, os achados revelam pontos importantes e que reforçam a capacidade de julgamento e tomada de decisão como habilidade do Contador. Outras limitações referem-se à aplicação da pesquisa com estudantes que não cursaram a disciplina de contabilidade internacional. Os conteúdos relacionados nas questões podem não ter sido objeto de estudo na disciplina de contabilidade internacional ou de outros componentes curriculares. Entende-se que novos estudos são necessários para maior aprofundamento no tema. Sugere-se investigar acadêmicos de outras Instituições de Ensino Superior para que os resultados possam ser comparados. O entendimento é de que pode haver resultados diferentes, na medida em que pesquisas forem realizadas com discentes de outras regiões e instituições.

\section{REFERÊNCIAS}

Bazerman, M. H. (2004). Processo decisório: para os cursos de administração e economia. Rio de Janeiro: Elsevier.

Birnberg, J.G. (2011). A Proposed Framework for Behavioral Accounting Research. Behavioral Research in Accounting, 23(1), 1-43.

Birnberg, J. G, Luft, J., \& Shields, M. (2007). Psychology Theory in Management Accounting Research. In C. S. Chapman, A. Hopwood, M. Shields (Orgs.). Handbook of Management Accounting Research.

César, A.M.V.C.; Akamine Junior, A. \& Perez, G. (2011, julho). Processos cognitivos envolvidos na estimativa de metas orçamentárias: um estudo nas áreas de logística e do Transporte Rodoviário de Cargas. Anais do Congresso Usp de Contabilidade e Controladoria, São Paulo, SP, Brasil, 11.

Comitê de Pronunciamentos Contábeis (2009). Pronunciamento Técnico CPC 30: Receitas. Brasília, 2009. Recuperado em 10 agosto, 2012, de http://www.cpc.org.br/CPC/Documentos-Emitidos/Pronunciamentos

Comitê de Pronunciamentos Contábeis (2009). Pronunciamento Técnico CPC 36 (R1): Demonstrações consolidadas. Brasília. Recuperado em 10 agosto, 2012, de http://www.cpc.org.br/CPC/Documentos-Emitidos/Pronunciamentos 
Comitê de Pronunciamentos Contábeis (2009). Pronunciamento Técnico CPC 17: Contratos de construção - mensuração. Brasília. Recuperado em 10 agosto, 2012, de http://www.cpc.org.br/CPC/Documentos-Emitidos/Pronunciamentos.

Comitê de Pronunciamentos Contábeis (2009). Pronunciamento Técnico CPC PME (R1): IFRS para PMEs. Brasília. Recuperado em 10 agosto, 2012, de http://www.cpc.org.br/CPC/Documentos-Emitidos/Pronunciamentos

Comitê de Pronunciamentos Contábei (2010). Pronunciamento Técnico CPC 07 (R1): Subvenção governamental. Brasília. Recuperado em 10 agosto, 2012, de http://www.cpc.org.br/CPC/Documentos-Emitidos/Pronunciamentos

Conselho Federal de Contabilidade (2012). Exame de Qualificação Técnica e Exame de Suficiência. Recuperado em 10 agosto, 2012, de http://www.portalcfc.org.br/coordenadorias/desenvolvimento_profissional/exames/exame_ de_qualificacao_tecnical

Creswel, J. W. (2007). Projeto de pesquisa: métodos qualitativo, quantitativo e misto (2a. ed.). Porto Alegre: Artmed.

Dantas, J.A., Niyama, J. K., Rodrigues, F. F., \& Mendes, P. C. (2010). Normatização contábil baseada em princípios ou em regras? Benefícios, custos, oportunidades e riscos. Revista de Contabilidade e Organizações, 4(9), 3-29.

Dantas, M. M. \& Macedo, M. A. (2013). O Processo Decisório no Ambiente Contábil: um estudo à luz da Teoria dos Prospectos. Revista de Contabilidade \& Controladoria, 5 (3), 47-65.

Dorow, A., Macedo Júnior, J. S., Nunes, P., Reina, D., \& Maximiniano, D. R. (2010). A heurística da ancoragem e a tomada de decisão sob risco em investimentos imobiliários. Contabilidade, Gestão e Governança, 13(3), 86-101.

Ernest Young \& Fipecafi (2010). Manual de Normas Internacionais de Contabilidade. IFRS versus normas brasileiras. São Paulo: Atlas.

Eysenck, M. W., \& Keane, M.T. (2007). Manual de psicologia cognitiva. (5a ed.). Porto Alegre: Artes médicas.

Gomes, L. F. A. M. (2007). Teoria da decisão. São Paulo: Thomson Learning.

Hastie, A. (2001). Problems for judgment and decision-making. Rev. Psychol, 52, 653-683.

ludícibus, S. de, Martins, E., Gelbcke, E.R., \& Santos, A. dos. (2010). Manual de contabilidade societária: aplicável a todas as sociedades de acordo com as normas internacionais e do CPC. São Paulo: Atlas.

Kaufmann, A. (1981). A ciência da tomada de decisão. Uma introdução à praxiologia. Rio de Janeiro: Zahar editores.

Kahneman, D. \& Tversky, A. (1979). Prospect Theory: An Analysis of Decision under Risk.

Econometrica, 47(2), 263-292.

Llima, D.H.S.de (2007). Efeito formulação e contabilidade: uma análise da influência da contabilidade na forma de apresentação dos demonstrativos e relatórios contábeis sobre o processo decisório dos usuários de informações contábeis. Dissertação de mestrado. Programa Pós-Graduação em Ciências Contábeis da UnB, UFPA e UFRN. Natal-RN, Brasil. Recuperado em 28 julho, 2012, de http://repositorio.unb.br/handle/10482/1222

Cardoso, R. L.\& Oyadomari, J.C (2010, setembro) A informação contábil e a fixação funcional: um estudo experimental considerando as alterações da lei 11.638/07. Anais do Encontro Nacional da Associação Nacional de Pós-Graduação e Pesquisa em Administração, Rio de Janeiro, Brasil, 34. 
Macedo, M. A. S., \& Fontes, P. V. S. (2009). Análise do Comportamento Decisório de Analistas Contábil-Financeiros: um estudo com base na Teoria da Racionalidade Limitada. Revista Contemporânea de Contabilidade. 11(1), 159-186.

Maia, K. I. C. (2012). O ensino de julgamento e tomada de decisão nos cursos de graduação em ciências contábeis no Brasil. Dissertação de mestrado. Escola Brasileira de Administração Pública e Empresas- EBAPE - FGV. São Paulo, Brasil. Recuperado em 29 julho, 2012, de http://bibliotecadigital.fgv.br/dspace/handle/10438/9909

Marin, R.(2009). Aplicação de um modelo cognitivo para análise de tomada de decisão em um ambiente de desenvolvimento orçamentário. Dissertação de mestrado. Universidade Presbiteriana Mackenzie. São Paulo, Brasil. Recuperado em 25 julho, 2012, de http://tede.mackenzie.br/jspui/handle/tede/2672

Martins, E., Martins, V.A., \& Martins, E.A. (2007). Normatização contábil: ensaio sobre sua evolução e o papel do CPC. Revista de Informação Contábil, 1(1), 7-30.

Matlin, M. W. (2003). Psicologia cognitiva. (5a ed). Rio de Janeiro: LTC.

Moreira, F. S., Firmino, J. E., Santos, A. R. D., Silva, J. D. G., \& Silva, M. C. (2015). Qualidade da Auditoria no Brasil: Um Estudo do Julgamento dos Auditores Independentes na Aderência do Ajuste a Valor Presente nas Companhias de Construção e Engenharia Listadas na BM\&F-Bovespa. Sociedade, Contabilidade e Gestão, 10(1), 62-80.

Niyama, J. K., Botelho, D. R., Correa, B. M., \& Santana, C. M. (2008). Conhecimento de contabilidade internacional nos cursos de graduação em ciências contábeis: estudo da oferta nas instituições de ensino superior das capitais brasileiras. Revista de Contabilidade e Organizações, 2(2), 100-117.

Pinto, P. S. B. (2012). O processo de decisão em ambiente contábil sob a ótica da Teoria dos Prospectos. Dissertação de mestrado. Universidade do Estado do Rio de Janeiro. Rio de Janeiro- RJ, Brasil. Recuperado em 23 abril, 2013, de http://bdtd.ibict.br/vufind/Record/UERJ_d03183a841aca8fa81e8ed07312f3b1c

Robbins, S. P. (2004). Comportamento Organizacional. (9a ed.). São Paulo: Prentice Hall.

Silva, A. C., \& Gonçalves, R.C.M.G. (2006, julho). Caracterização do uso de sistemas de controle orçamentário: um estudo multicaso. Anais do Congresso USP de Contabilidade e Controladoria, São Paulo, USP, Brasil, 6.

Sternberg, R. J. (2010). Psicologia cognitiva. (5a ed). Rio de Janeiro: Cengage Learning.

Xavier Filho, J. L. J., Dias, S. A., França, F. M., Silva, A. C. B., \& Vasconcelos, A. F. (2015). A importância dos conhecimentos contábeis para os discentes em administração: uma análise a partir de influentes de julgamento. Revista de Gestão, Finanças e Contabilidade, 5(1) 77-104. 